\title{
Synthesis of $\mathrm{V}_{2} \mathrm{O}_{5}$ Nanoflakes on PET Fiber as
} Visible-Light-Driven Photocatalysts for Degradation of RhB Dye

\author{
Yim-Leng Chan, Swee-Yong Pung, and Srimala Sreekantan \\ Science and Engineering of Nanomaterials Team, School of Materials and Mineral Resources Engineering, Universiti Sains Malaysia, \\ Engineering Campus, Seri Ampangan, 14300 Nibong Tebal, Pulau Pinang, Malaysia \\ Correspondence should be addressed to Swee-Yong Pung; sypung@usm.my
}

Received 26 May 2014; Revised 27 July 2014; Accepted 28 July 2014; Published 17 August 2014

Academic Editor: Adel A. Ismail

Copyright (C) 2014 Yim-Leng Chan et al. This is an open access article distributed under the Creative Commons Attribution License, which permits unrestricted use, distribution, and reproduction in any medium, provided the original work is properly cited.

The visible-light-driven semiconductor photocatalysts are the current research focus techniques used to decompose organic pollutants/compounds. The photodegradation efficiency of organic compounds by photocatalyst is expected to be better compared to UV-light-driven semiconductor photocatalysts technique since the major components of our solar energy are visible light $(\sim 44 \%)$. However, as most of the previous research work has been carried out using semiconductor photocatalysts in the form of powder, extra steps and costs are needed to remove this powder from the slurry to prevent secondary pollution. In this research work, we will explain our fabrication technique of $\mathrm{V}_{2} \mathrm{O}_{5}$ nanoflakes by growing radially on PET fibers. By utilizing the flexibility and high surface area of polymeric fibers as novel substrate for the growth of $\mathrm{V}_{2} \mathrm{O}_{5}$ nanoflakes, the Rhodamine $\mathrm{B}$ (RhB) could be degraded under visible light irradiation. The photodegradation of RhB solution by $\mathrm{V}_{2} \mathrm{O}_{5}$ nanoflakes followed the 1st order kinetic with a constant rate of $0.0065 \mathrm{~min}^{-1}$. The success of this research work indicates that $\mathrm{V}_{2} \mathrm{O}_{5}$ nanoflakes grown on PET fibre could be possibly used as organic waste water purifier under continuous flow condition. A photodegradation mechanism of $\mathrm{V}_{2} \mathrm{O}_{5}$ nanostructures to degrade $\mathrm{RhB}$ dye is proposed based on the energy diagram.

\section{Introduction}

Water pollution is one of the most serious environmental problems. Many untreated organic effluents such as dyes from textile industries are being discharged into the ecosystem, creating severe environmental pollution by releasing toxic and potential carcinogenic substances into the environment [1]. Therefore, various wastewater treatment processes such as precipitation, adsorption by activated carbon, coagulation, and membrane ultrafiltration have been developed for the removal of these organic pollutants [2-5]. However, these wastewater treatment processes are simply transforming the pollutants from one phase to another, leading to secondary pollution problems.

Recently, there has been a growing interest in the utilization of advanced oxidation processes (AOPs) via semiconductor photocatalysts for the organic pollutants removal. In AOPs, highly reactive species such as hydroxyl radicals are generated to oxidize a broad range of organic pollutants rapidly and nonselectively. Semiconductor photocatalysts are widely used due to their unique strengths for complete mineralization of organic pollutants into less harmful byproduct such as water, $\mathrm{CO}_{2}$, and mineral acids. For example, zinc oxide $(\mathrm{ZnO})$ nanoparticles [6-10] and titanium oxide $\left(\mathrm{TiO}_{2}\right)$ nanoparticles [11-13] were frequently used by researchers as UV-driven photocatalysts to decompose organic compounds/pollutants because of their wide band gap.

Development of visible-light-driven semiconductor photocatalysts for organic compounds removal is our current research focus. This is because the visible light accounts for $45 \%$ of the total energy of solar spectrum, while UV light only represents less than $10 \%$. Theoretically, the photodegradation efficiency of organic compounds by semiconductor photocatalysts in visible light irradiation could be further enhanced. Several methods have been explored to develop visible-lightdriven semiconductor photocatalysts. This could be done by shifting the band gap absorption edge of wide band gap semiconductors to a longer wavelength via metal or nonmetal doping. For example, $\mathrm{Cu}$ doped $\mathrm{ZnO}$ nanorods [14] and $\mathrm{Cd}$ doped $\mathrm{ZnO}$ nanostructures [15] responded to visible light 
irradiation in degradation of organic dyes. Furthermore, narrow band gap semiconductor such as manganese oxide $\left(\mathrm{MnO}_{2}\right)$ nanoparticles $[16,17]$ and vanadium dioxide $\left(\mathrm{VO}_{2}\right)$ nanoparticles [18] could also be used as visible-light-driven photocatalysts. Normally, $\mathrm{H}_{2} \mathrm{O}_{2}$ chemical was required to improve the photodegradation efficiency of these semiconductor photocatalysts in degradation of organic compounds under visible light irradiation [19].

Regardless of UV- or visible-light-driven photocatalysts, most of the previous research used semiconductor in the form of nanoparticles for organic compounds removal. This is because semiconductor nanoparticles collectively have a high surface area, resulting in effective generation of free radicals and decomposition of organic compounds. The limitation of using semiconductor nanoparticles is that there is a need for the removal of nanoparticles from the slurry via centrifugation [20]. This addition step is time consuming and adds extra cost to the overall process. This additional processing step for the removal of semiconductor nanoparticles can be avoided by growing semiconductor nanostructures rigid substrates such as stainless steel wire [21].

In this work, vanadium pentoxide $\left(\mathrm{V}_{2} \mathrm{O}_{5}\right)$ was selected as visible-light-driven semiconductor to be grown on flexible substrate, that is, polyethylene terephthalate (PET) fibre attributed to its narrow band gap $(2.52 \mathrm{eV})$. There are various synthesis methods that could be used to produce the $\mathrm{V}_{2} \mathrm{O}_{5}$ nanostructures and thin films. For instances, Wei and Zhang synthesized $\mathrm{V}_{2} \mathrm{O}_{5}$ nanotubes using hydrothermal method [22] and Yin et al. grew porous $\mathrm{V}_{2} \mathrm{O}_{5}$ micro/nanotubes by chemical vapor deposition [23]. In addition, Blanquart et al. deposited $\mathrm{V}_{2} \mathrm{O}_{5}$ thin films using atomic layer deposition [24] and Gotić et al. synthesized $\mathrm{V}_{2} \mathrm{O}_{5}$ powder by sol-gel method [25]. As the $\mathrm{V}_{2} \mathrm{O}_{5}$ nanoflakes were to be grown on PET fibre, sol-gel method was chosen because of its low synthesis temperature $\left(<100^{\circ} \mathrm{C}\right)$ and possibility of upscaling the synthesis process.

The synthesis condition of $\mathrm{V}_{2} \mathrm{O}_{5}$ nanoparticles using solgel method was first established. Subsequently, this synthesis condition was applied to synthesize $\mathrm{V}_{2} \mathrm{O}_{5}$ nanoflakes on PET fibre. The PET fibre offers more flexibility in handling as compared to stainless steel wire during setting up organic waste purifier. The photocatalytic activities of both $\mathrm{V}_{2} \mathrm{O}_{5}$ nanoparticles and $\mathrm{V}_{2} \mathrm{O}_{5}$ nanoflakes which have grown on PET fibre in degradation of $\mathrm{RhB}$ dye $\left(\mathrm{C}_{28} \mathrm{H}_{31} \mathrm{ClN}_{2} \mathrm{O}_{3}\right)$ under visible light irradiation were studied.

\section{Material and Methods}

$\mathrm{V}_{2} \mathrm{O}_{5}$ nanoparticles were synthesized by vanadium acetylacetone $\left(\mathrm{VO}(\mathrm{acac})_{2}\right)$ and hexadecylamine $\left(\mathrm{CH}_{3}\left(\mathrm{CH}_{2}\right)_{15} \mathrm{NH}_{2}\right)$ as precursors. The solution mixture with the molar ratio of $\mathrm{VO}(\mathrm{acac})_{2}$ and $\mathrm{CH}_{3}\left(\mathrm{CH}_{2}\right)_{15} \mathrm{NH}_{2}=2: 1$ was stirred for $1 \mathrm{~h}$ at $60^{\circ} \mathrm{C}$. Then, it was heated at $90^{\circ} \mathrm{C}$ for $20 \mathrm{~h}$. Finally, the nanoparticles were filtered and dried at oven.

Similar synthesis condition was used for the synthesis of $\mathrm{V}_{2} \mathrm{O}_{5}$ nanoflakes on PET fiber. In this work, $\mathrm{a}_{2} \mathrm{O}_{5}$ seed layer was predeposited on the PET fiber to facilitate the growth of $\mathrm{V}_{2} \mathrm{O}_{5}$ nanostructures. The seed layer was deposited using a sol solution which contained of $0.015 \mathrm{~mol}$ of vanadium oxide

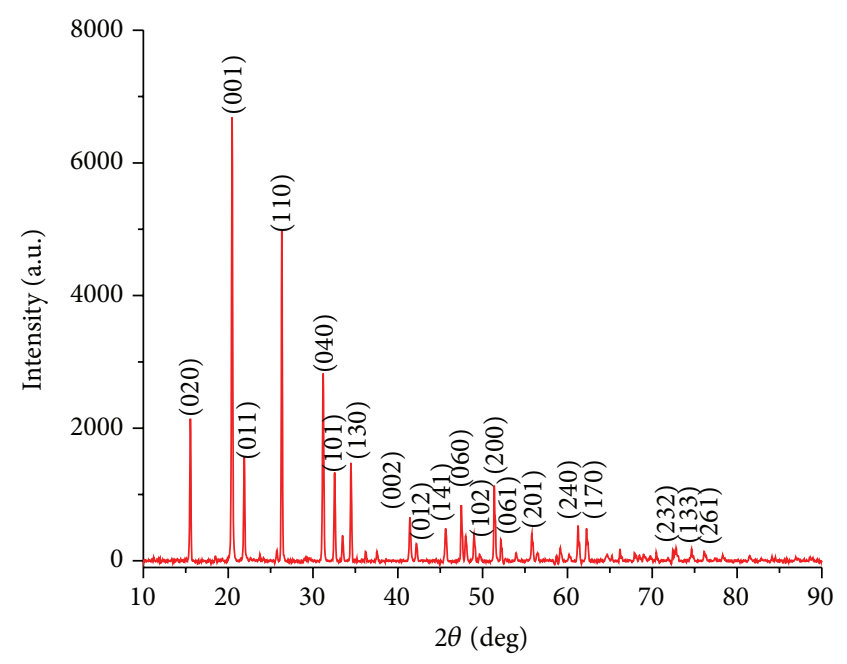

FIGURE 1: XRD pattern of $\mathrm{V}_{2} \mathrm{O}_{5}$ nanoparticles prepared by sol-gel method.

and $30 \mathrm{wt} \%$ of hydrogen peroxide. The mixture was stirred for $1.5 \mathrm{~h}$. Subsequently, the PET fiber which is precoated with 1 dodecanethiol was immersed into the sol solution for $15 \mathrm{~min}$. Then, the fiber was dried in oven. This step was repeated for 3 times to ensure the $\mathrm{V}_{2} \mathrm{O}_{5}$ seed was uniformly coated on the fiber. Next, the fiber with $\mathrm{V}_{2} \mathrm{O}_{5}$ seed layer was immersed into the $\mathrm{VO}(\mathrm{acac})_{2}$ and $\mathrm{CH}_{3}\left(\mathrm{CH}_{2}\right)_{15} \mathrm{NH}_{2}$ solution for $20 \mathrm{~h}$ at $90^{\circ} \mathrm{C}$ for the growth of $\mathrm{V}_{2} \mathrm{O}_{5}$ nanoflakes.

The morphologies of the nanostructures were examined using a Zeiss Supra 35 VP field emission scanning electron microscope (FESEM). The phase and crystallinity of the nanoparticles were characterized using a Philip PW 1729 $\mathrm{X}$-ray diffractometer $(\mathrm{Cu} \mathrm{K}, \lambda=0.154 \mathrm{~nm})$. The band gap of nanoparticles was determined by Perkin UV-Vis spectrometer. The effectiveness of $\mathrm{V}_{2} \mathrm{O}_{5}$ nanostructures to degrade $1.0 \times 10^{-5} \mathrm{M}$ of $\mathrm{RhB}$ solution under visible light was evaluated. A UV cutoff filter was used to remove any radiation below $400 \mathrm{~nm}$ and to ensure illumination by visible light only. The estimated $\mathrm{V}_{2} \mathrm{O}_{5}$ nanostructures used in this study were $15 \mathrm{mg}$. The degraded $\mathrm{RhB}$ solution was characterized by measuring the $553 \mathrm{~nm}$ absorption spectra of $\mathrm{RhB}$ using Cary 50 UV-Vis spectroscopy. In a separate experiment, isopropanol (IPA), which served as $\mathrm{OH}$ radical scavengers, was added into the $\mathrm{RhB}$ solution to study the role of $\mathrm{OH}$ radicals in this photocatalytic reaction.

\section{Results and Discussion}

3.1. $\mathrm{V}_{2} \mathrm{O}_{5}$ Nanoparticles and Their Photocatalytic Activity. The XRD pattern of the nanoparticles is shown in Figure 1. The XRD pattern could be indexed to $\mathrm{V}_{2} \mathrm{O}_{5}$ (JCPDS no. 60-0767). The diffraction peaks at $15.6^{\circ}, 20.4^{\circ}, 21.9^{\circ}, 26.3^{\circ}, 31.2^{\circ}, 32.6^{\circ}$, $34.5^{\circ}, 41.4^{\circ}, 42.3^{\circ}, 45.6^{\circ}, 47.5^{\circ}, 49.0^{\circ}, 51.4^{\circ}, 52.3^{\circ}, 55.8^{\circ}, 61.2^{\circ}$, and $62.3^{\circ}$ corresponded to (020), (001), (011), (110), (040), (101), (130), (002), (012), (141), (060), (102), (200), (061), (201), (240), and (170) planes, respectively. No diffraction peaks for other elements were detected. The narrow and intense diffraction peaks reveal that the $\mathrm{V}_{2} \mathrm{O}_{5}$ nanoparticles were 


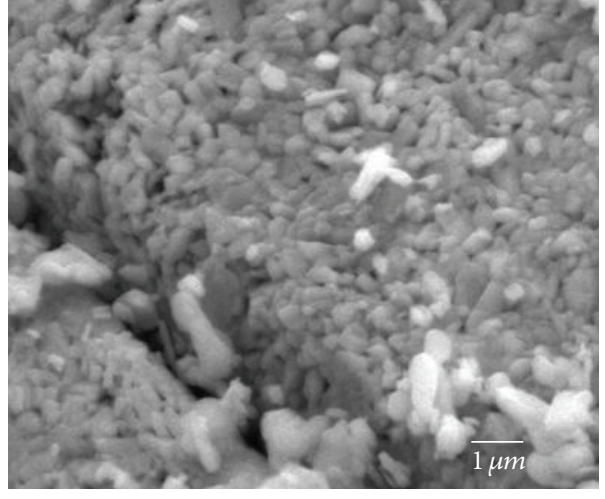

(a)

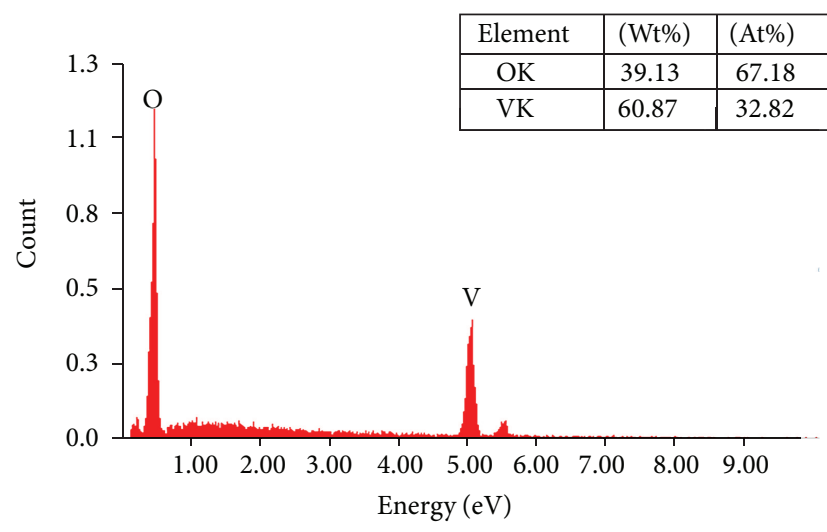

(b)

FIGURE 2: (a) SEM image and (b) EDX spectrum of $\mathrm{V}_{2} \mathrm{O}_{5}$ nanoparticles.

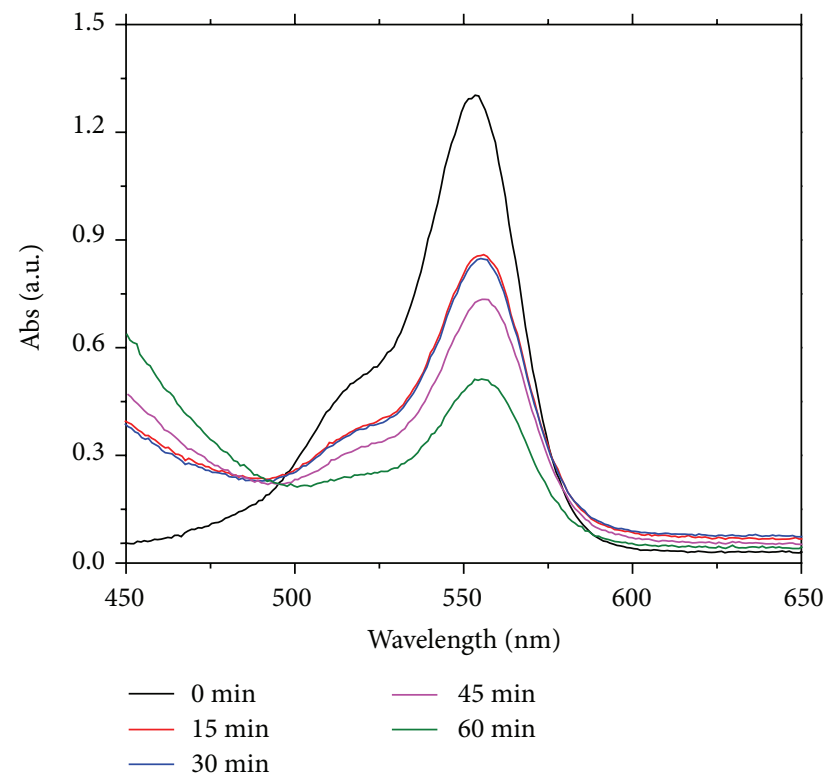

FIGURE 3: Absorbance spectra of RhB aqueous solution degraded by $\mathrm{V}_{2} \mathrm{O}_{5}$ nanoparticles under visible light irradiation.

highly crystalline. The calculated size of $\mathrm{V}_{2} \mathrm{O}_{5}$ nanoparticles based on Scherrer equation was $53.5 \mathrm{~nm}$. The morphology of $\mathrm{V}_{2} \mathrm{O}_{5}$ nanoparticles was determined by SEM image as shown in Figure 2(a). The $\mathrm{V}_{2} \mathrm{O}_{5}$ nanoparticles were rod-like with average length of $231.9 \pm 14.9 \mathrm{~nm}$. The EDX analysis as shown in Figure 2(b) indicates that there are no other impurity elements, besides $\mathrm{V}$ and $\mathrm{O}$ elements. The atomic percentage of $\mathrm{V}$ and $\mathrm{O}$ is $32.82 \%$ and $67.18 \%$, respectively, which is close to the stoichiometric ratio of $\mathrm{V}_{2} \mathrm{O}_{5}$.

The effectiveness of $\mathrm{V}_{2} \mathrm{O}_{5}$ nanoparticles to degrade $\mathrm{RhB}$ solution under visible light was evaluated and is shown in Figure 3. The degraded $\mathrm{RhB}$ solution by $\mathrm{V}_{2} \mathrm{O}_{5}$ nanoparticles was characterized by measuring the $553 \mathrm{~nm}$ absorption spectra of RhB using Cary $50 \mathrm{UV}$-Vis spectroscopy. The intensity

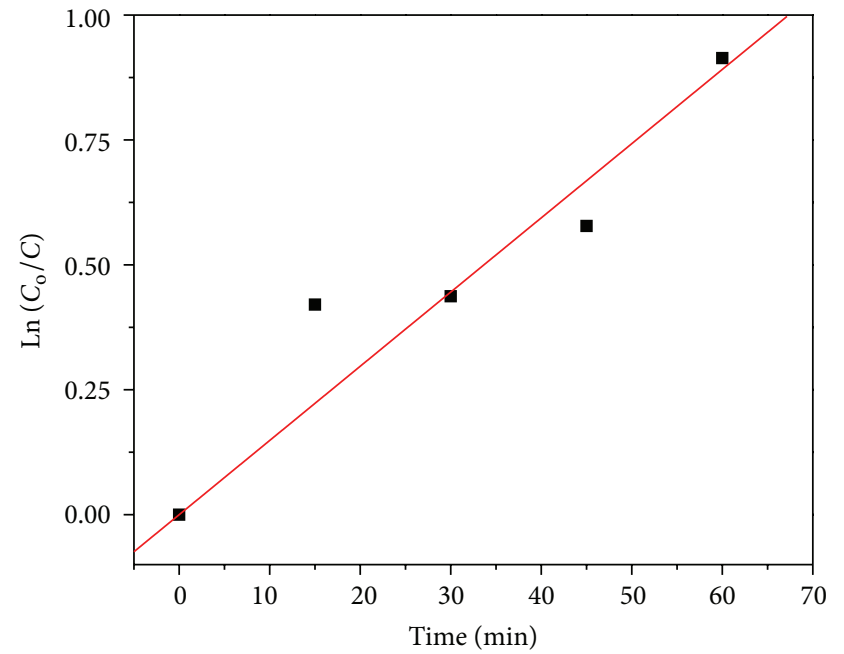

FIGURE 4: Photodegradation of $\mathrm{RhB}$ solution by $\mathrm{V}_{2} \mathrm{O}_{5}$ nanoparticles under visible light irradiation.

of the $553 \mathrm{~nm}$ absorption peak decreased as a function of irradiation time from $1.293 \mathrm{a}$.u. (initial absorbance) to 0.849 a.u. after $15 \mathrm{~min}$ and further decreased to 0.518 a.u. after $60 \mathrm{~min}$. The decrease of this absorption peak was due to the breaking of the conjugated $\pi$-system in $\mathrm{RhB}$ chain by free radicals. This phenomenon is known as cycloreversion.

According to Lambert-beer law, the concentration of the solution $(C)$ is proportional to the absorption spectrum (A). Thus, this allows the data to be replotted as a $\ln \left(C_{o} / C\right)$ versus irradiation time graph, as shown in Figure 4. The linear plot of $\ln \left(C_{o} / C\right)$ versus irradiation time indicates that degradation of $\mathrm{RhB}$ solution by $\mathrm{V}_{2} \mathrm{O}_{5}$ nanoparticles under visible light irradiation follows the first order kinetic. The rate constant of photodegradation of $\mathrm{RhB}$ by $\mathrm{V}_{2} \mathrm{O}_{5}$ nanoparticles under visible light irradiation, which could be determined from the slope of the graph, is $0.0149 \mathrm{~min}^{-1}$ (std. error $=0.0013$ and $R$ square $=0.9611$ ). This result suggests that $\mathrm{V}_{2} \mathrm{O}_{5}$ nanoparticles 


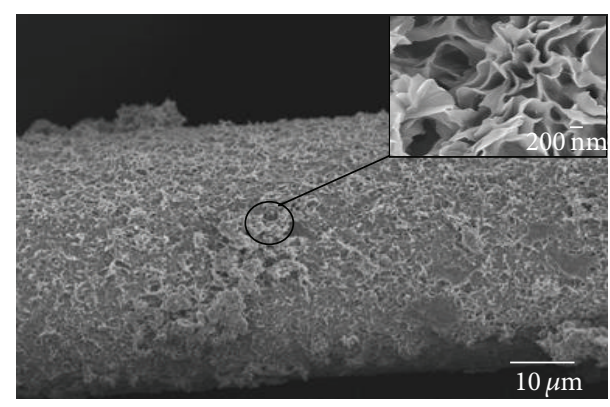

(a)

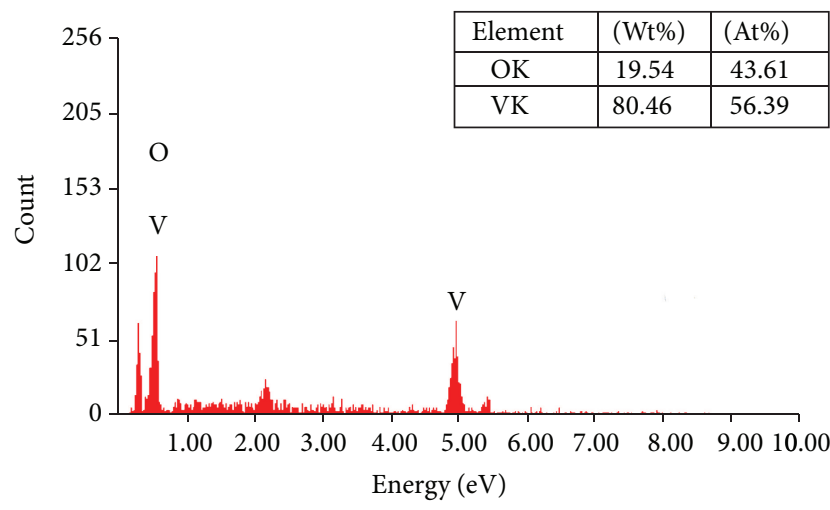

(b)

FIgURE 5: (a) SEM images and (b) EDX spectrum of $\mathrm{V}_{2} \mathrm{O}_{5}$ nanoflakes grown on PET fiber.

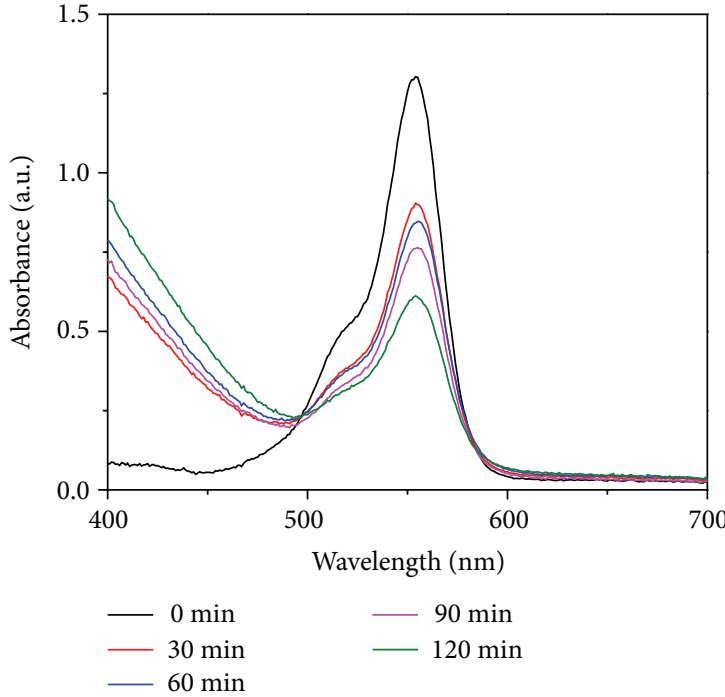

(a)

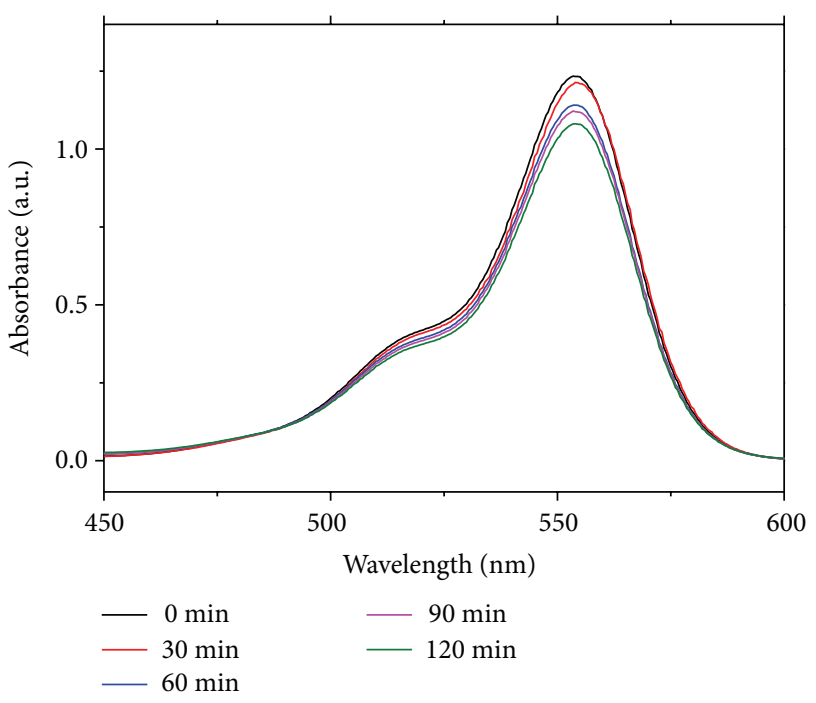

(b)

FIgURE 6: Absorbance spectra of RhB aqueous solution (a) without and (b) with IPA degraded by $\mathrm{V}_{2} \mathrm{O}_{5}$ nanoflakes grown on PET fiber after visible light irradiation.

are visible-light-driven semiconductor photocatalysts. The photodegradation mechanism of $\mathrm{RhB}$ solution using $\mathrm{V}_{2} \mathrm{O}_{5}$ nanoparticles will be discussed in Section 3.3.

\section{2. $\mathrm{V}_{2} \mathrm{O}_{5}$ Nanoflakes Grown on PET Fiber and Their Photo-} catalytic Activity. $\mathrm{V}_{2} \mathrm{O}_{5}$ nanoflakes were grown on PET fiber using the preestablished synthesis condition from Section 3.1. As shown in Figure 5(a), the PET fiber was fully covered by $\mathrm{V}_{2} \mathrm{O}_{5}$ nanoflakes. The thickness of the nanoflakes was in the range of 5-20 nm as shown in the inset of Figure 5(a). The EDX analysis in Figure 5(b) indicates that the main elements of the nanoflakes are $\mathrm{V}$ and $\mathrm{O}$ with the atomic percentage of $56.39 \%$ and $43.61 \%$, respectively. No other impurity elements could be detected in the $\mathrm{V}_{2} \mathrm{O}_{5}$ nanoflakes.

The effectiveness of $\mathrm{V}_{2} \mathrm{O}_{5}$ nanoflakes grown on PET fiber to degrade $\mathrm{RhB}$ solution under visible light was evaluated. The color of RhB solution was faded gradually after being exposed to visible light as shown by the UV-Vis absorption spectrum of RhB solution in Figure 6(a). The intensity of the $553 \mathrm{~nm}$ absorbance peak of RhB decreased from 1.293 a.u. (initial absorbance) to $0.895 \mathrm{a}$.u. after $30 \mathrm{~min}$ irradiation. It is further reduced to 0.838 a.u. after $60 \mathrm{~min}$ and 0.608 a.u. after $120 \mathrm{~min}$ irradiation. The linear plot of $\ln \left(C_{o} / C\right)$ versus irradiation time in Figure 7(a) indicates that photodegradation of $\mathrm{RhB}$ by $\mathrm{V}_{2} \mathrm{O}_{5}$ nanoflakes under visible light irradiation follows the first order kinetic. The rate constant for $\mathrm{V}_{2} \mathrm{O}_{5}$ nanoflakes on PET fiber to degrade $\mathrm{RhB}$ solution under visible light irradiation is $0.0065 \mathrm{~min}^{-1}$ (std. error $=0.0006$ and $R$-square $=0.9842$ ). Although the rate constant of using $\mathrm{V}_{2} \mathrm{O}_{5}$ nanoflakes on PET fiber to degrade $\mathrm{RhB}$ solution under visible light is smaller than the rate constant using $\mathrm{V}_{2} \mathrm{O}_{5}$ nanoparticles, the result proved that the $\mathrm{V}_{2} \mathrm{O}_{5}$ nanoflakes could still degrade the RhB solution after growing on the PET fiber. Thus, the application of $\mathrm{V}_{2} \mathrm{O}_{5}$ nanoflakes grown on PET 


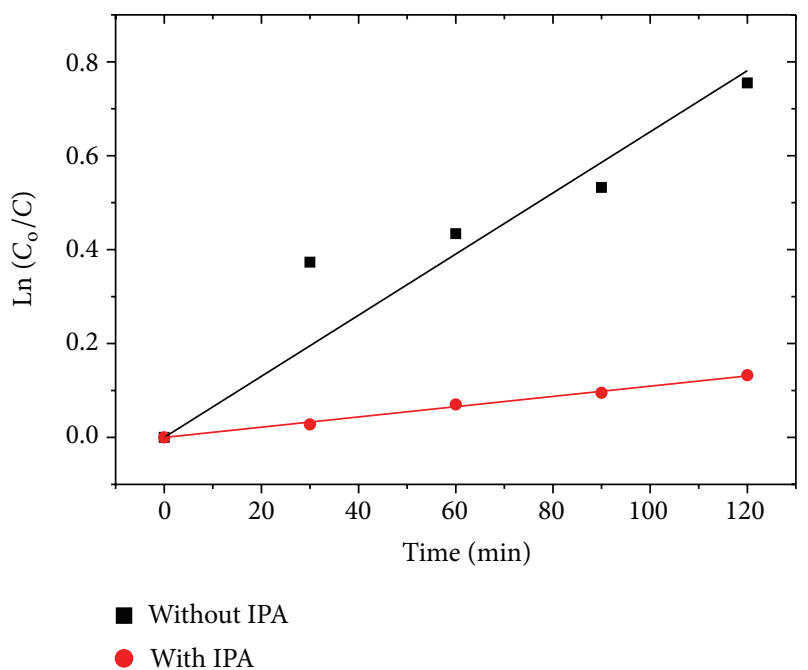

FIgURE 7: Photodegradation of RhB solution (a) without and (b) with IPA by $\mathrm{V}_{2} \mathrm{O}_{5}$ nanoflakes grown on PET fiber under visible light irradiation.

fiber to degrade organic pollutants in flowing water such as river is possible.

The photodegradation of $\mathrm{RhB}$ solution was deteriorated by $\mathrm{V}_{2} \mathrm{O}_{5}$ nanoflakes on PET fiber under visible light irradiation with the mixing of IPA as shown in Figures 6(b) and 7(b). The rate constant of the reaction with IPA is $0.0011 \mathrm{~min}^{-1}$ (std. error $=0.0002$ and $R$-square $=0.999$ ). As IPA is known as an $\mathrm{OH}$ free radical scavenger [26, 27], the significant decrease of rate constant indicates that the photodegradation of $\mathrm{RhB}$ solution was dominant by the $\mathrm{OH}$ free radicals that were generated by $\mathrm{V}_{2} \mathrm{O}_{5}$ nanoflakes on PET fiber under visible light irradiation.

3.3. Photodegradation Mechanism of RhB Solution by $V_{2} \mathrm{O}_{5}$ under Visible Light Irradiation. The photodegradation of $\mathrm{RhB}$ solution by $\mathrm{V}_{2} \mathrm{O}_{5}$ could be explained by adsorptionoxidation-desorption mechanism. The optical band gap of $\mathrm{V}_{2} \mathrm{O}_{5}$ nanoparticles measured by UV-Vis spectrometer is $2.41 \mathrm{eV}$ as indicated in Figure 8. The $E_{v}$ and $E_{c}$ of $\mathrm{V}_{2} \mathrm{O}_{5}$ nanoparticles in NHE are $0.40 \mathrm{eV}$ and $2.81 \mathrm{eV}$, respectively, as shown in Figure 9. This result is in good agreement with the reported values by Miyauchi et al. and Viswanathan [21, 28]. As illustrated in Figure 9, the band edge of conduction band $\left(E_{c}\right)$ of $\mathrm{V}_{2} \mathrm{O}_{5}$ nanoparticles is more positive to the absolute electronegativity of oxygen $(-0.046 \mathrm{eV})$. Thus, the excited electrons $\left(e_{c b}^{-}\right)$in the conduction band do not favor for the reduction of oxygen molecules into $\mathrm{O}_{2}{ }^{-}$free radicals. However, the band edge of valence band $\left(E_{v}\right)(2.81 \mathrm{eV})$ is more positive than the oxidation potential of water $(1.99 \mathrm{eV})$. In this case, the holes $\left(h_{v b}^{+}\right)$are able to produce $\mathrm{OH}^{*}$ free radicals [29-31]. These free radicals are responsible for the degradation of $\mathrm{RhB}$ dye into less harmful byproduct such as water as shown in (1)-(3). Generally, $\mathrm{V}_{2} \mathrm{O}_{5}$ nanoparticles and nanoflakes took a longer time to decolorize the $\mathrm{RhB}$ solution as compared to $\mathrm{ZnO}$ [6-10] and $\mathrm{TiO}_{2}$ [11-13]. The slower photodegradation efficiency was likely attributed to

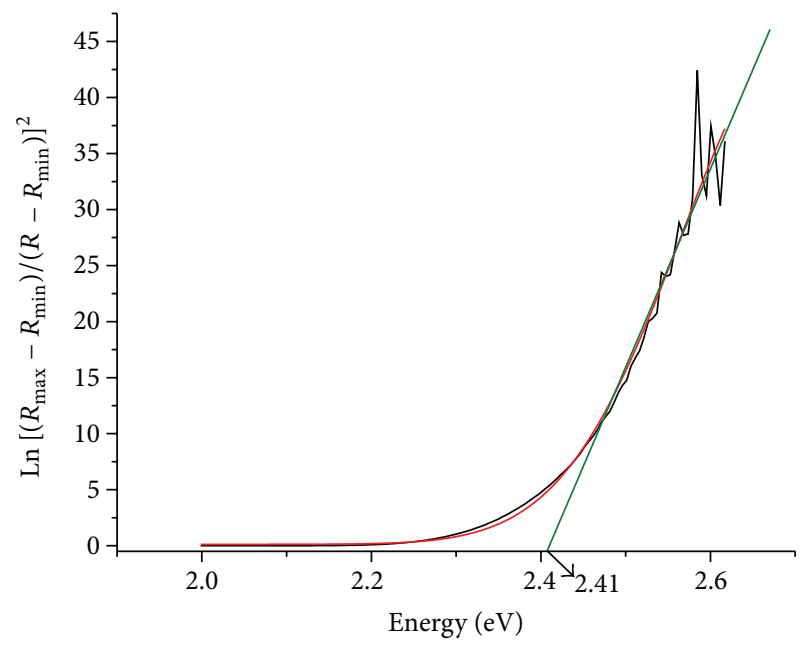

FIGURE 8: The band gap of $\mathrm{V}_{2} \mathrm{O}_{5}$ nanoparticles.

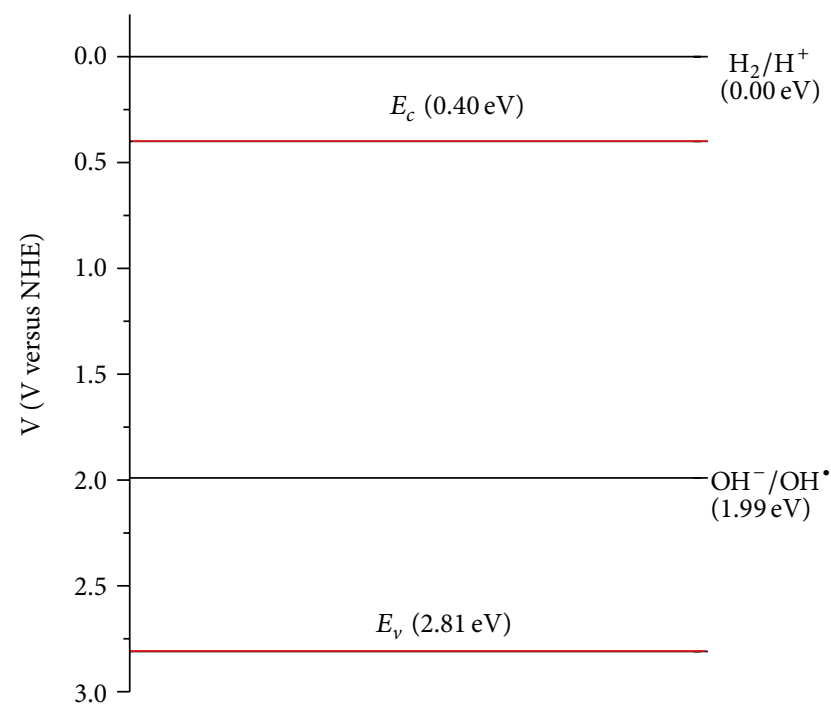

Figure 9: The band structure model of $\mathrm{V}_{2} \mathrm{O}_{5}$.

the limited number of free radicals produced by $\mathrm{V}_{2} \mathrm{O}_{5}$ as only the photogenerated holes were able to produce free radicals. Consider the following:

$$
\begin{gathered}
\mathrm{V}_{2} \mathrm{O}_{5}+h v \longrightarrow h_{v b}^{+}+e_{c b}^{-} \\
h_{v b}^{+}+\mathrm{H}_{2} \mathrm{O} \longrightarrow \mathrm{H}^{+}+\mathrm{OH}^{\bullet}
\end{gathered}
$$

$\mathrm{RhB}$ dye $+\mathrm{O}_{2}^{\cdot-}+\mathrm{OH}^{\bullet} \longrightarrow$ byproducts

\section{Conclusions}

$\mathrm{V}_{2} \mathrm{O}_{5}$ nanoparticles and $\mathrm{V}_{2} \mathrm{O}_{5}$ nanoflakes on fiber were successfully synthesized via sol-gel method. The $\mathrm{V}_{2} \mathrm{O}_{5}$ nanoparticles were rod-like with average length of $231.9 \pm 14.9 \mathrm{~nm}$, whereas the thickness of the nanoflakes was in the range of 5-20 nm. The photocatalytic activities for both $\mathrm{V}_{2} \mathrm{O}_{5}$ nanoparticles and $\mathrm{V}_{2} \mathrm{O}_{5}$ nanoflakes grown on fiber were 
$0.0149 \mathrm{~min}^{-1}$ and $0.0065 \mathrm{~min}^{-1}$, respectively, under visible light irradiation. These results indicate that both $\mathrm{V}_{2} \mathrm{O}_{5}$ nanostructures could be used as visible-light-driven photocatalysts to remove organic pollutants. The slow photodegradation rate of $\mathrm{V}_{2} \mathrm{O}_{5}$ nanostructures to degrade $\mathrm{RhB}$ dye under visible light irradiation is proposed due to the slow free radicals $\left(\mathrm{OH}^{*}\right)$ generation rate as only the photogenerated holes are positively enough to produce $\mathrm{OH}^{\bullet}$ based on the energy diagram.

\section{Conflict of Interests}

The authors declare that there is no conflict of interests regarding the publication of this paper.

\section{Acknowledgments}

The authors would like to acknowledge the USM Postgraduate Research Grant Scheme (PRGS) (1001/PBAHAN/ 8036010) and the USM Research University Grant (RU) (1001/PBAHAN/814200) for the financial support to conduct this project.

\section{References}

[1] B. Neppolian, H. C. Choi, S. Sakthivel, B. Arabindoo, and V. Murugesan, "Solar/UV-induced photocatalytic degradation of three commercial textile dyes," Journal of Hazardous Materials, vol. 89, no. 2-3, pp. 303-317, 2002.

[2] G. S. Gupta, G. Prasad, and V. N. Singh, "Removal of chrome dye from aqueous solutions by mixed adsorbents: fly ash and coal," Water Research, vol. 24, no. 1, pp. 45-50, 1990.

[3] A. Rozzi, M. Antonelli, and M. Arcari, "Membrane treatment of secondary textile effluents for direct reuse," Water Science and Technology, vol. 40, no. 4-5, pp. 409-416, 1999.

[4] L. Xu, W. Li, S. Lu, Z. Wang, Q. Zhu, and Y. Ling, “Treating dyeing waste water by ceramic membrane in crossflow microfiltration," Desalination, vol. 149, no. 1-3, pp. 199-203, 2002.

[5] J. Mo, J. Hwang, J. Jegal, and J. Kim, "Pretreatment of a dyeing wastewater using chemical coagulants," Dyes and Pigments, vol. 72, no. 2, pp. 240-245, 2007.

[6] N. Daneshvar, S. Aber, M. S. Seyed Dorraji, A. R. Khataee, and M. H. Rasoulifard, "Preparation and investigation of photocatalytic properties of $\mathrm{ZnO}$ nanocrystals: effect of operational parameters and kinetic study," World Academy of Science Engineering and Technology, vol. 29, pp. 267-272, 2007.

[7] R. Y. Hong, J. H. Li, L. L. Chen et al., "Synthesis, surface modification and photocatalytic property of $\mathrm{ZnO}$ nanoparticles," Powder Technology, vol. 189, no. 3, pp. 426-432, 2009.

[8] J. Xie, Y. Li, W. Zhao, L. Bian, and Y. Wei, "Simple fabrication and photocatalytic activity of $\mathrm{ZnO}$ particles with different morphologies," Powder Technology, vol. 207, no. 1-3, pp. 140144, 2011.

[9] S. N. Q. A. Abd Aziz, S. Y. Pung, N. N. Ramli, and Z. Lockman, "Growth of $\mathrm{ZnO}$ nanorods on stainless steel wire using chemical vapour deposition and their photocatalytic activity," The Scientific World Journal, vol. 2014, Article ID 252851, 9 pages, 2014.

[10] Y. L. Chan, S. Y. Pung, and S. Sreekantan, "Degradation of organic dye using $\mathrm{ZnO}$ nanorods based continuous flow water purifier," Journal of Sol-Gel Science and Technology, vol. 66, no. 3, pp. 399-405, 2013.
[11] T. G. Smijs and S. Pavel, "Titanium dioxide and zinc oxide nanoparticles in sunscreens: Focus on their safety and effectiveness," Nanotechnology, Science and Applications, vol. 4, no. 1, pp. 95-112, 2011.

[12] H. A. Bullen and S. J. Garrett, $\mathrm{TiO}_{2}$ Nanoparticles for Photocatalysis, Michigan State University, East Lansing, Mich, USA, 2003.

[13] H. Esfahani, A. H. Javadi, M. A. Farahmandnejad, P. Nourpour, and K. Shabani, "Study on kinetic of UV and solar assisted photocatalytic degradation of rhodamine $\mathrm{B}$ by $\mathrm{TiO}_{2}$ nanostructure layer," Materials Technology, vol. 27, no. 3, pp. 261-266, 2012.

[14] R. Mohan, K. Krishnamoorthy, and S. Kim, "Enhanced photocatalytic activity of $\mathrm{Cu}$-doped $\mathrm{ZnO}$ nanorods," Solid State Communications, vol. 152, no. 5, pp. 375-380, 2012.

[15] D. Zhang and F. Zeng, "Visible light-activated cadmiumdoped $\mathrm{ZnO}$ nanostructured photocatalyst for the treatment of methylene blue dye," Journal of Materials Science, vol. 47, no. 5, pp. 2155-2161, 2012.

[16] J. H. Cheng, G. Shao, H. J. Yu, and J. J. Xu, "Excellent catalytic and electrochemical properties of the mesoporous $\mathrm{MnO}_{2}$ nanospheres/nanosheets," Journal of Alloys and Compounds, vol. 505, no. 1, pp. 163-167, 2010.

[17] J. Ge and J. Qu, "Degradation of azo dye acid red B on manganese dioxide in the absence and presence of ultrasonic irradiation," Journal of Hazardous Materials, vol. 100, no. 1-3, pp. 197-207, 2003.

[18] Y. Wang, Z. Zhang, Y. Zhu et al., "Nanostructured $\mathrm{VO}_{2}$ photocatalysts for hydrogen production," ACS Nano, vol. 2, no. 7, pp. 1492-1496, 2008.

[19] S. R. Segal, S. L. Suib, X. Tang, and S. Satyapal, "Photoassisted decomposition of dimethyl methylphosphonate over amorphous manganese oxide catalysts," Chemistry of Materials, vol. 11, no. 7, pp. 1687-1695, 1999.

[20] F. D. Mai, C. C. Chen, J. L. Chen, and S. C. Liu, "Photodegradation of methyl green using visible irradiation in $\mathrm{ZnO}$ suspensions: determination of the reaction pathway and identification of intermediates by a high-performance liquid chromatography-photodiode array-electrospray ionizationmass spectrometry method," Journal of Chromatography A, vol. 1189, no. 1-2, pp. 355-365, 2008.

[21] M. Miyauchi, A. Nakajima, T. Watanabe, and K. Hashimoto, "Photocatalysis and photoinduced hydrophilicity of various metal oxide thin films," Chemistry of Materials, vol. 14, no. 6, pp. 2812-2816, 2002.

[22] J. Wei and J. Zhang, "Hydrothermal synthesis and characterization of vanadium oxide nanotubes," Advanced Materials Research, vol. 11-12, pp. 535-538, 2006.

[23] H. Yin, K. Yu, H. Peng et al., "Porous $\mathrm{V}_{2} \mathrm{O}_{5}$ micro/nano-tubes: synthesis via a CVD route, single-tube-based humidity sensor and improved Li-ion storage properties," Journal of Materials Chemistry, vol. 22, no. 11, pp. 5013-5019, 2012.

[24] T. Blanquart, J. Niinistö, M. Gavagnin et al., "Atomic layer deposition and characterization of vanadium oxide thin films," RSC Advances, vol. 3, no. 4, pp. 1179-1185, 2013.

[25] M. Gotić, S. Popović, M. Ivanda, and S. Musić, "Sol-gel synthesis and characterization of $\mathrm{V}_{2} \mathrm{O}_{5}$ powders," Materials Letters, vol. 57, no. 21, pp. 3186-3192, 2003.

[26] N. Serpone, D. Lawless, R. Khairutdinov, and E. Pelizzetti, "Subnanosecond relaxation dynamics in $\mathrm{TiO}_{2}$ colloidal sols (particle sizes $\mathrm{R}_{\mathrm{p}}=1.0-13.4 \mathrm{~nm}$ ). Relevance to heterogeneous photocatalysis," Journal of Physical Chemistry, vol. 99, no. 45, pp. 16655-16661, 1995. 
[27] R. A. Palominos, M. A. Mondaca, A. Giraldo, G. Peñuela, M. Pérez-Moya, and H. D. Mansilla, "Photocatalytic oxidation of the antibiotic tetracycline on $\mathrm{TiO}_{2}$ and $\mathrm{ZnO}$ suspensions," Catalysis Today, vol. 144, no. 1-2, pp. 100-105, 2009.

[28] B. Viswanathan, Photo-Electrochemical Processes-Principles and Possibilities, National Centre for Catalysis Research Indian Institute of Technology Madras, Chennai, India, 2011.

[29] B. Pan, Y. Xie, S. Zhang, L. Lv, and W. Zhang, "Visible light photocatalytic degradation of RhB by polymer-CdS nanocomposites: role of the host functional groups," ACS Applied Materials and Interfaces, vol. 4, no. 8, pp. 3938-3943, 2012.

[30] W. K. Burton, N. Cabrera, and F. C. Frank, "The growth of crystals and the equilibrium structure of their surfaces," The Philosophical Transactions of the Royal Society A, vol. 243, pp. 299-358, 1951.

[31] J. Fu, Y. Tian, B. Chang, F. Xi, and X. Dong, "BiOBr-carbon nitride heterojunctions: synthesis, enhanced activity and photocatalytic mechanism," Journal of Materials Chemistry, vol. 22, no. 39, pp. 21159-21166, 2012. 

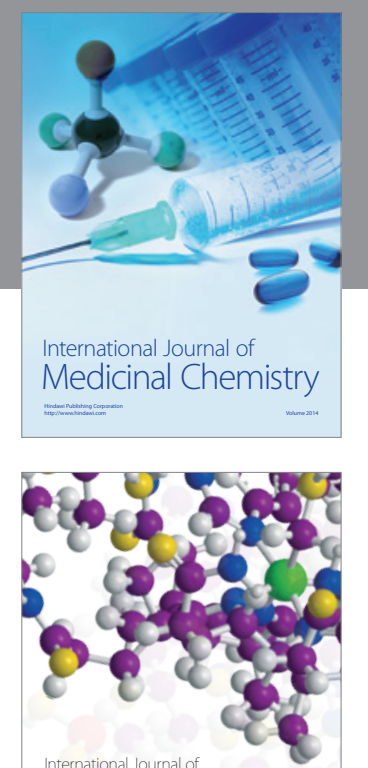

\section{Carbohydrate} Chemistry

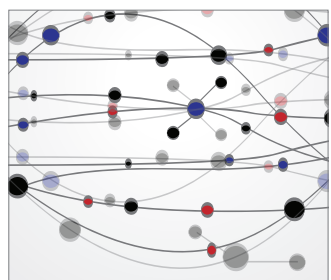

The Scientific World Journal
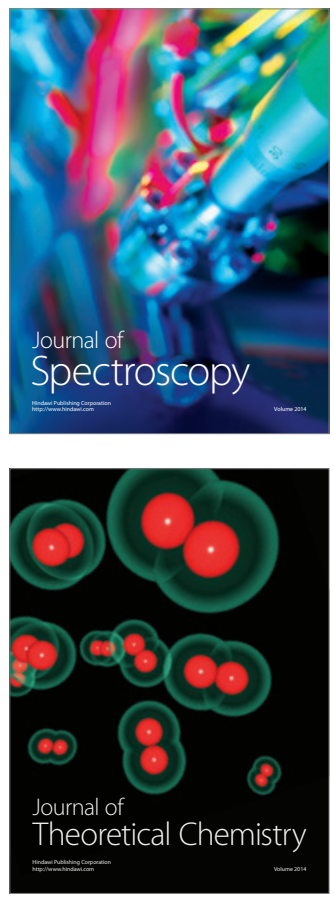
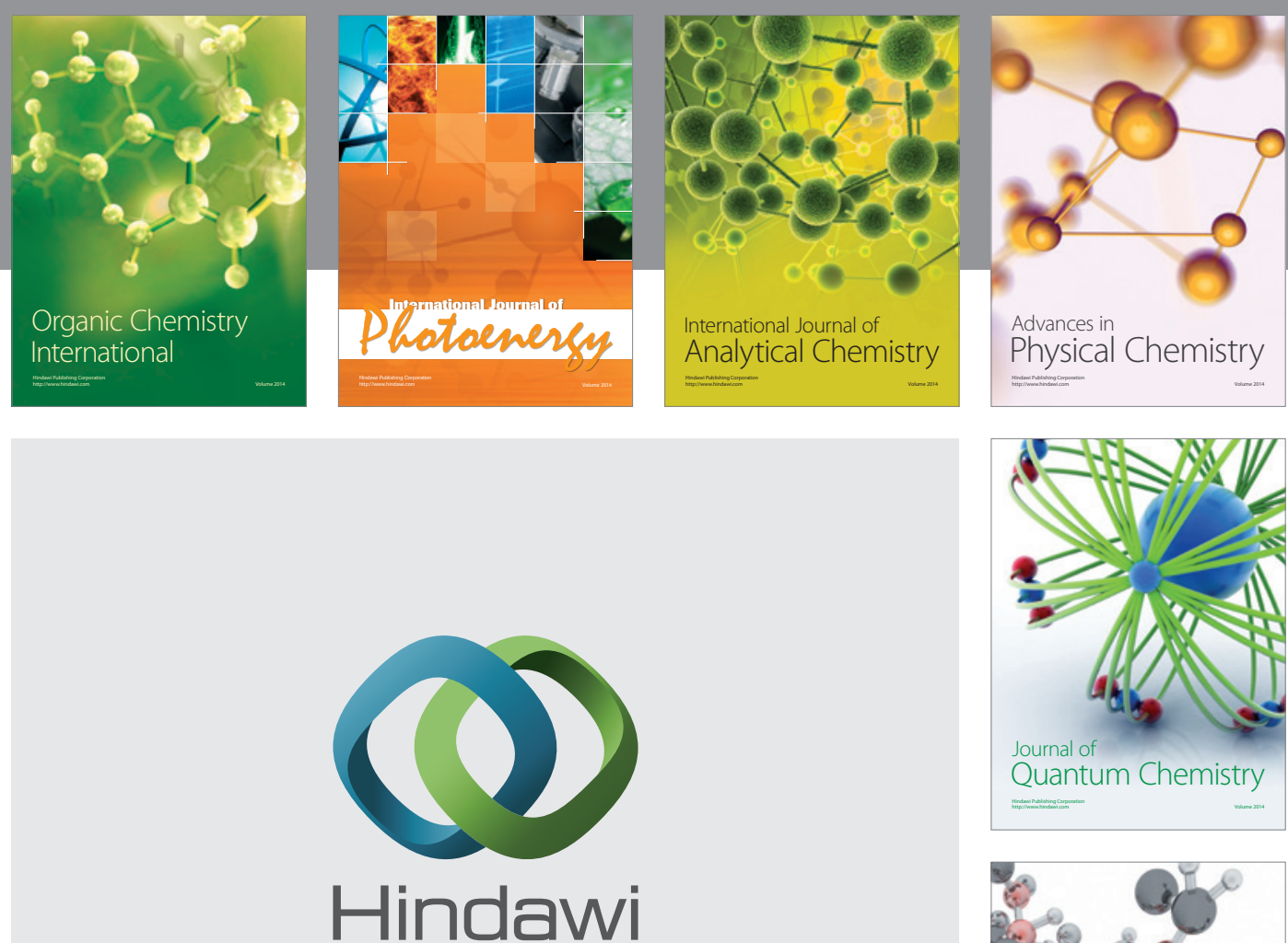

Submit your manuscripts at

http://www.hindawi.com

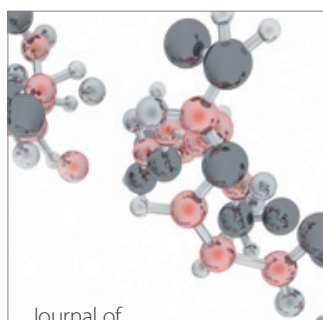

Analytical Methods

in Chemistry

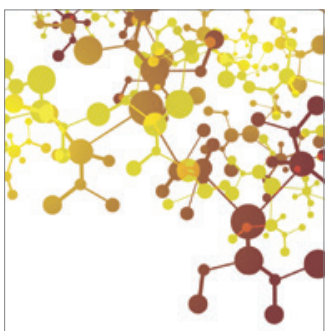

Journal of

Applied Chemistry

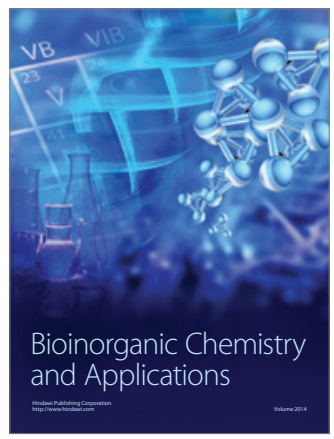

Inorganic Chemistry
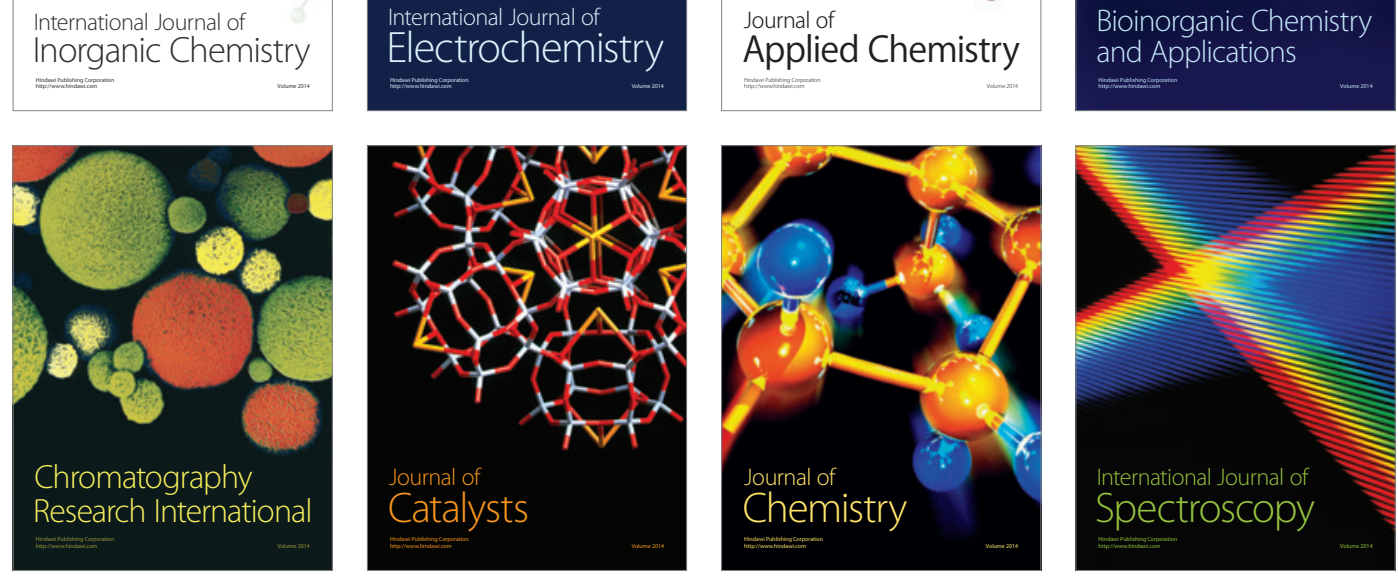